\title{
Comment on "Early presentation of urinary retention in multiple system atrophy: can the disease begin in the sacral spinal cord?"
}

\author{
Divyani Garg ${ }^{1}$ (1) $\cdot$ Ayush Agarwal ${ }^{2}$
}

Received: 25 November 2019 / Accepted: 27 November 2019 / Published online: 5 December 2019

c) Springer-Verlag GmbH Germany, part of Springer Nature 2019

\section{Dear Sirs,}

We read with great interest the paper "Early presentation of urinary retention in multiple system atrophy: can the disease begin in the sacral spinal cord?" [1]

The paper highlights the presentation of six patients with predominant urinary retention followed by development of multiple system atrophy (MSA) 1-7 years later.

A prion-like spread of misfolded endogenous alpha-synuclein through the central nervous system has been suggested for MSA as well as other alpha-synucleinopathies [2, 3]. However, none of the studies endeavoring to demonstrate alpha-synuclein spread have provided a clear conclusion [4]. The study by Panicker et al. points towards the pathology initiating in the sacral spinal cord. That this subset went on to develop the classical motor symptoms that met the diagnostic criteria for MSA may serve as indirect clinical evidence in favor of the spread of alpha-synuclein pathology.

Another possibility is that this series represent a subset of patients with pure autonomic failure with urinary dysfunction instead of cardiovascular dysautonomia who later phenoconverted into MSA? Did these patients demonstrate any other features of autonomic dysfunction other than genitourinary autonomic dysfunction involvement? Three of the six patients had orthostatic hypotension. However, detailed cardiovascular autonomic function tests would have helped to assess the extent of autonomic dysfunction, further characterizing this phenotype.

This comment refers to the article available online at https://doi. org/10.1007/s00415-019-09597-2.

Divyani Garg

divyanig@gmail.com

1 Department of Neurology, Lady Hardinge Medical College, New Delhi, India

2 Department of Neurology, Dr. Ram Manohar Lohia Institute of Medical Sciences, Lucknow, India
We congratulate the authors on these preliminary significant observations. However, larger prospective studies of this patient subset will enable an answer to the above questions.

\section{Compliance with ethical standards}

Conflicts of interest The authors declare that they have no conflict of interests.

Ethical standards This article does not contain any studies with human participants or animals performed by any of the authors.

\section{References}

1. Panicker JN, Simeoni S, Miki Y, Batla A, Iodice V, Holton JL et al (2019) Early presentation of urinary retention in multiple system atrophy: can the disease begin in the sacral spinal cord? J Neurol. https://doi.org/10.1007/s00415-019-09597-2

2. Watts JC, Giles K, Oehler A, Middleton L, Dexter DT, Gentleman SM et al (2013) Transmission of multiple system atrophy prions to transgenic mice. Proc Natl Acad Sci USA 110(48):19555-19560. https://doi.org/10.1073/pnas.1318268110

3. Dhillon J-KS, Trejo-Lopez JA, Riffe C, Levites Y, Sacino AN, Borchelt DR et al (2019) Comparative analyses of the in vivo induction and transmission of $\alpha$-synuclein pathology in transgenic mice by MSA brain lysate and recombinant $\alpha$-synuclein fibrils. Acta Neuropathol Commun 7(1):80. https://doi.org/10.1186/ s40478-019-0733-3

4. Wenning G, Trojanowski JQ, Kaufmann H, Wisniewski T, Rocca WA, Low PA (2018) Is multiple system atrophy an infectious disease? Ann Neurol 83(1):10-12. https://doi.org/10.1002/ana.25132 